(6) OPEN ACCESS

Department of Epidemiology and Public Health, University College London, London, UK

\section{Correspondence to}

Dr Mark Hamer, Department of Epidemiology and Public Health, 1-19 Torrington Place, University College London, London WC1E 6BT, UK; m.hamer@ucl.ac.uk

Accepted 27 March 2012

Published Online First 12 July 2012

\title{
Longitudinal patterns in physical activity and sedentary behaviour from mid-life to early old age: a substudy of the Whitehall II cohort
}

\author{
Mark Hamer, Mika Kivimaki, Andrew Steptoe
}

\begin{abstract}
Background There are few longitudinal data on physical activity patterns from mid-life into older age. The authors examined associations of self-reported physical activity, adiposity and socio-demographic factors in mid-life with objectively assessed measures of activity in older age. Methods Participants were 394 healthy men and women drawn from the Whitehall II population-based cohort study. At the baseline assessment in 1997 (mean age 54 years), physical activity was assessed through self-report and quantified as metabolic equivalent of task hours/week. At the follow-up in 2010 (mean age 66 years), physical activity was objectively measured using accelerometers worn during waking hours for seven consecutive days (average daily wear time $891 \pm 68 \mathrm{~min} /$ day).
\end{abstract}

Results Self-reported physical activity at baseline was associated with objectively assessed activity at follow-up in various activity categories, including light-, moderateand vigorous-intensity activity (all ps<0.04). Participants in the highest compared with lowest quartile of selfreported activity level at baseline recorded on average 64.1 (95\% Cl 26.2 to 102.1) counts per minute more accelerometer-assessed activity at follow-up and 9.0 (2.0-16.0) $\mathrm{min} /$ day more moderate-to-vigorous daily activity, after adjusting for baseline covariates. Lower education, obesity and self-perceived health status were also related to physical activity at follow-up. Only age and education were associated with objectively measured sedentary time at follow-up

Conclusion Physical activity behaviour in middle age was associated with objectively measured physical activity in later life after 13 years of follow-up, suggesting that the habits in adulthood are partly tracked into older age.

\section{INTRODUCTION}

Physical activity is important for maintaining health in older age ${ }^{1-3}$ although relatively little is known about changes in physical activity behaviour over the life course, especially the transition from mid-life to older age. Transition from primary to secondary school, ${ }^{4}$ transition from high school to college or university, ${ }^{5}$ marriage, ${ }^{6}$ becoming a parent ${ }^{7}$ and retirement ${ }^{8}$ have all been suggested as important factors for change in physical activity behaviour. However, most of the existing research on physical activity patterns in older adults has been cross-sectional, and few studies have tracked individuals longitudinally from mid-life into older age.

Numerous factors might be important in determining physical activity behaviour across the life course, including socioeconomic circumstances, the environment, physical and mental health and other lifestyle-related factors. For example, in the British Women's Heart and Health Study, low socioeconomic position across the life course was associated with an increased risk of physical inactivity in older age. ${ }^{9}$ Also, in an Australian cohort study, upward social mobility from childhood to adulthood (defined in this study as reaching a higher level of educational attainment than one's parents) was associated with greater likelihood of increasing activity and fitness over the life course. ${ }^{10}$

The aim of the present study was to examine associations of self-reported physical activity behaviour, socioeconomic and lifestyle factors in mid-life (baseline aged 54 years) with objectively assessed measures of activity in early old age (aged 66 years) over a 13-year follow-up period. We employed objective measures of physical activity that overcomes biases associated with self-reports, which are particularly evident when trying to recall non-structured everyday activities that might be relevant in older samples. ${ }^{11}$

\section{METHODS \\ Participants}

A sample of participants was drawn from the Whitehall II population-based cohort $^{12}$ for a substudy of objectively assessed physical activity in 2009/2010. The Whitehall II study is an ongoing prospective cohort study that consists of 10308 participants (6895 men and 3413 women aged 35-55 years) recruited from the British civil service in 1985 in order to investigate the importance of social class for health. The baseline medical examination (phase 1) took place during 1985-1988, and subsequent phases have alternated between questionnaire alone (phases 2, 4, 6 and 8) and phases including both a medical examination and a questionnaire (phases 1, 3, 5, 7 and 9). The criteria for entry into the substudy included no history or objective signs of coronary heart disease, no previous diagnosis or treatment for hypertension, inflammatory diseases or allergies. Volunteers were of white European origin. Selection was stratified by grade of employment (current or most recent) to include higher and lower socioeconomic status participants. Participants gave full informed consent to participate in the study, and ethical approval was obtained from the University College London Hospital (UCLH) committee on the Ethics of Human Research.

\section{Baseline assessments}

For the purposes of this study, baseline was considered as phase 5 (1997) of the Whitehall II study since 
this was the first time a detailed self-reported physical activity questionnaire was administered. The questionnaire consisted of 20 items on frequency and duration of participation in walking, cycling, sports, gardening, housework and home maintenance. ${ }^{13}$ Frequency and duration of each activity were combined to compute hours per week of physical activity. A compendium of activity energy costs was then used to derive a metabolic equivalent of task (MET) for each of the 20 physical activities assessed. Sedentary activity was assessed by enquiring about the time spent sitting at home. The self-reported physical activity questionnaire is a modified version of the previously validated Minnesota leisure-time physical activity questionnaire. ${ }^{14}$ In addition, the selfreported physical activity measure has demonstrated convergent validity in predicting mortality. ${ }^{15}$

At baseline, participants also reported current smoking habits, highest educational attainment, employment grade and general perceived health from the Medical Outcomes Study's ShortForm 36 Health Survey (SF-36). ${ }^{16}$ Height and weight were recorded in light clothing for the calculation of body mass index (BMI).

\section{Physical activity at follow-up}

At a subsequent assessment in 2009/2010, participants were asked to wear an accelerometer (Actigraph GT3X, FL, USA) around the waist that records movement on the vertical and horizontal axis, during waking hours for seven consecutive days. The accelerometer provides a measure of the frequency, intensity and duration of physical activity and allows classification of activity levels as sedentary, light, moderate and vigorous. The raw accelerometry data were processed using specialist software (MAHUffe, Cambridge, UK) to produce a series of standardised outcome variables. All participants included in the present analysis recorded a minimum of $10 \mathrm{~h} /$ day wear time for 6-7 days. The first and last days of data were excluded from the analysis, and non-wear time was defined as intervals of at least 60 consecutive minutes of 0 counts per minute (cpm). We used cut-off points previously used in an older sample of adults ${ }^{17}$ to calculate daily times in each activity intensity band: sedentary activity (<1.5 MET): 0-199 cpm; light activity (1.5-3 MET) 200-1999 cpm; moderate activity (3-6 MET): 2000-3999 cpm; vigorous activity (>6 MET): $\geq 4000 \mathrm{cpm}$. Sensitivity analyses were also performed using a more conservative cut point of $0 \mathrm{cpm}$ to differentiate sedentary time from activity. ${ }^{18}$ All physical activity variables were converted to time (in minutes) per valid day. Participants also completed daily diaries to record non-wear time and participation in water-based activities such as swimming that cannot be recorded by the Actigraph device.

\section{Statistical analysis}

Self-reported moderate-to-vigorous physical activity at baseline was quantified as MET-h/week and then categorised into four equal groups, which was treated as the main exposure variable. Self-reported physical activity was also examined in separate domains, including light ( $<3 \mathrm{MET})$, moderate $(3-6 \mathrm{MET})$ and vigorous ( $>6 \mathrm{MET}$ ) intensity. Various indices of physical activity from the Actigraph data at follow-up were used as the dependent variable: counts per minute; total activity time; light, moderate and vigorous activity; and combined moderateto-vigorous physical activity. All these indices were normally distributed and used as continuous variables in all statistical models. We employed simple Pearson correlation to explore associations between physical activity at baseline and follow-up. General linear models were then used to examine the associa- tions further, making adjustments for age, sex, BMI, smoking, employment grade, education and general health perception. All analyses were conducted using SPSS V.15 using two-sided tests, with a significance level $\mathrm{p}<0.05$.

\section{RESULTS}

From the initial sample of 510 participants, 64 did not provide Actigraph data and 52 had missing demographic data from baseline and were excluded from the analysis. Thus, the analytic sample comprised 394 men and women. The excluded participants who did not provide Actigraph data were marginally younger (52.6 vs 54.1 years, $p=0.048$ ) than those included, although did not differ on other characteristics such as baseline levels of self-reported moderate-to-vigorous physical activity. Baseline characteristics of the sample are shown in table 1. On average, the sample displayed low rates of smoking and obesity, and physical activity was relatively high.

At follow-up, $59.8 \%$ of men and $49.3 \%$ of women recorded at least $30 \mathrm{~min} /$ day of moderate-to-vigorous physical activity, and a summary of the Actigraph data is provided in table 2. Selfreported physical activity at baseline was associated with objectively assessed activity at follow-up in various domains, including light (Pearson's $r=0.14, p=0.004)$, moderate $(r=0.10$, $\mathrm{p}=0.034)$ and vigorous $(\mathrm{r}=0.10, \mathrm{p}=0.037)$ activity, although there were no correlations between self-reported and objective sedentary time.

In multivariate analysis, baseline levels of self-reported moderate-to-vigorous physical activity remained independently associated with objectively assessed physical activity at followup after controlling for age, sex, BMI, smoking, employment grade, education and general health perception at baseline (tables 3 and 4). For example, participants in the highest compared with lowest quartile of self-reported activity level at baseline recorded on average 64.1 (95\% CI 26.2 to 102.1) cpm more accelerometerassessed activity at follow-up and $9.0(2.0-16.0) \mathrm{min} /$ day more moderate-to-vigorous daily activity, after adjusting for baseline covariates. Participants in the highest compared with lowest quartile of self-reported physical activity at baseline recorded on

Table 1 Characteristics of the study population at baseline $(\mathrm{N}=394)$ Variable

\begin{tabular}{lc}
\hline Age (years \pm SD) & $54.0 \pm 5.4$ \\
Men, $\mathrm{n}(\%)$ & $196(49.7)$ \\
Smoking, $\mathrm{n}(\%)$ & \\
$\quad$ Never & $216(54.8)$ \\
$\quad$ Ex & $147(37.3)$ \\
$\quad$ Current & $31(7.9)$ \\
Work grade, $\mathrm{n}(\%)$ & \\
$\quad$ Lowest & $81(20.6)$ \\
Intermediate & $155(39.3)$ \\
$\quad$ Highest & $158(40.1)$ \\
Highest educational qualification, $\mathrm{n}(\%)$ & \\
$\quad$ None & $31(7.9)$ \\
$\quad$ O-level/A-level & $219(55.6)$ \\
$\quad$ Degree or higher & $144(36.5)$ \\
Self-reported $\mathrm{MVPA}(\mathrm{MET}-\mathrm{h} / \mathrm{week})$ & $34.1 \pm 18.6$ \\
Self-reported sitting at home $(\mathrm{h} / \mathrm{week})$ & $6.8 \pm 2.6$ \\
BMI category, $\mathrm{n}(\%)$ & \\
$\quad$ Normal weight $\left(<25 \mathrm{~kg} / \mathrm{m}^{2}\right)$ & $230(58.4)$ \\
$\quad$ Overweight $\left(25 \mathrm{to}<30 \mathrm{~kg} / \mathrm{m}^{2}\right)$ & $144(36.5)$ \\
$\quad$ Obese $\left(\geq 30 \mathrm{~kg} / \mathrm{m}^{2}\right)$ & $20(5.1)$
\end{tabular}

BMI, body mass index; MET, metabolic equivalent of task; MVPA, moderate-to-vigorous physical activity. 
Table 2 Summary of Actigraph data $(\mathrm{N}=394)$

\begin{tabular}{lc}
\hline Variable & \\
\hline Average counts per minute & $323.7 \pm 138.1(10.6-884.1)$ \\
Total daily active time (min/day) & $274.4 \pm 93.9(1.0-552.7)$ \\
Daily sedentary time (min/day) & $643.1 \pm 88.1(424.6-1360.0)$ \\
Daily light activity (min/day) & $210.2 \pm 66.4(1.0-457.0)$ \\
Daily moderate-to-vigorous activity (min/day) & $37.2 \pm 25.5(0-153.0)$ \\
Daily wear time (min/day) & $890.6 \pm 68.3(669.4-1361.0)$ \\
\hline
\end{tabular}

Values are presented as means $\pm S D$ (range).

average 28 (6.6-49.4) $\mathrm{min} /$ day more total activity at follow-up, after adjusting for other covariates (see figure 1). Also participants in the highest compared with lowest quartile of selfreported physical activity at baseline recorded on average 29.4

Table 3 Predictors of physical activity (in counts per minute) at follow-up $(\mathrm{N}=394)$

\begin{tabular}{|c|c|c|}
\hline Variable & $\mathbf{N}$ & $\begin{array}{l}\text { Multivariate adjusted } \\
\beta(95 \% \mathrm{CI})\end{array}$ \\
\hline \multicolumn{3}{|l|}{ Age, years } \\
\hline$<50$ & 128 & Ref \\
\hline $50-55$ & 138 & $-30.8(-62.7$ to 1.2$)$ \\
\hline$>55$ & 128 & $-82.1(-115.3$ to -88.8 \\
\hline $\mathrm{p}$ Value & & $<0.001$ \\
\hline \multicolumn{3}{|l|}{ Sex } \\
\hline Men & 196 & Ref \\
\hline Women & 198 & $-10.6(-37.6$ to 16.4$)$ \\
\hline $\mathrm{p}$ Value & & 0.44 \\
\hline \multicolumn{3}{|l|}{ Self-reported MVPA quartile } \\
\hline Lowest ( $<20 \mathrm{MET}$-h/week) & 100 & Ref \\
\hline Low-moderate (20-30 MET-h/week) & 93 & $33.6(-3.3$ to 70.5$)$ \\
\hline Moderate-high (31-43 MET-h/week) & 99 & $55.7(18.4$ to 93.0$)$ \\
\hline Highest (>43 MET-h/week) & 102 & $64.1(26.2$ to 102.1$)$ \\
\hline $\mathrm{p}$ Value & & 0.005 \\
\hline \multicolumn{3}{|l|}{ Smoking status } \\
\hline Never smoked & 216 & Ref \\
\hline Ex-smoker & 147 & $-5.6(-33.2$ to 22.0$)$ \\
\hline Current smoker & 31 & $-25.7(-77.3$ to 26.0$)$ \\
\hline $\mathrm{p}$ Value & & 0.61 \\
\hline \multicolumn{3}{|l|}{ BMI category } \\
\hline Normal weight $\left(<25 \mathrm{~kg} / \mathrm{m}^{2}\right)$ & 230 & Ref \\
\hline Overweight $\left(25\right.$ to $\left.<30 \mathrm{~kg} / \mathrm{m}^{2}\right)$ & 144 & $-37.9(-65.4$ to -10.4$)$ \\
\hline Obese $\left(\geq 30 \mathrm{~kg} / \mathrm{m}^{2}\right)$ & 20 & $-62.7(-102.8$ to -2.6$)$ \\
\hline p Value & & 0.008 \\
\hline \multicolumn{3}{|l|}{ Work grade } \\
\hline Lowest & 81 & Ref \\
\hline Intermediate & 155 & $-15.8(-31.7$ to 31.5$)$ \\
\hline Highest & 158 & $-13.8(-55.2$ to 27.6$)$ \\
\hline $\mathrm{p}$ Value & & 0.77 \\
\hline \multicolumn{3}{|l|}{ Highest educational qualification } \\
\hline None & 31 & Ref \\
\hline O-level/A-level & 219 & $44.9(-9.9$ to 99.7$)$ \\
\hline Degree or higher & 144 & $73.9(12.7$ to 135.0$)$ \\
\hline p Value & & 0.04 \\
\hline \multicolumn{3}{|l|}{ SF-36 General health perception } \\
\hline Lowest $(<67)$ & 113 & Ref \\
\hline Low-moderate $(67-77)$ & 115 & $-12.0(-46.3$ to 22.2$)$ \\
\hline Moderate (77-87) & 86 & $17.3(-19.9$ to 54.6$)$ \\
\hline High $(>87)$ & 80 & $41.9(2.7$ to 81.1$)$ \\
\hline p Value & & 0.04 \\
\hline
\end{tabular}

Data are presented as unstandardised coefficients. $p$ Values reflect $p$ value for trend.

Model adjusted for age and mutually for all presented variables.

$\mathrm{BMI}$, body mass index; MET, metabolic equivalent of task; MVPA, moderate-to-vigorous physical activity; SF-36, Short-Form 36 Health Survey.
Table 4 Predictors of MVPA (min/day) at follow-up ( $\mathrm{N}=394)$

\begin{tabular}{|c|c|c|}
\hline Variable & $\mathbf{N}$ & $\begin{array}{l}\text { Multivariate adjusted } \\
\beta(95 \% \text { CI) }\end{array}$ \\
\hline \multicolumn{3}{|l|}{ Age, years } \\
\hline$<50$ & 128 & Ref \\
\hline $50-55$ & 138 & $-3.5(-9.4$ to 2.4$)$ \\
\hline$>55$ & 128 & $-14.6(-20.7$ to -8.5$)$ \\
\hline $\mathrm{p}$ Value & & $<0.001$ \\
\hline \multicolumn{3}{|l|}{ Sex } \\
\hline Men & 196 & Ref \\
\hline Women & 198 & $-3.7(-8.7$ to 1.3$)$ \\
\hline $\mathrm{p}$ Value & & 0.15 \\
\hline \multicolumn{3}{|l|}{ Self-reported MVPA quartile } \\
\hline Lowest (<20 MET-h/week) & 100 & Ref \\
\hline Low-moderate (20-30 MET-h/week) & 93 & $6.3(-0.5$ to 13.2$)$ \\
\hline Moderate-high (31-43 MET-h/week) & 99 & $9.9(3.0$ to 16.9$)$ \\
\hline Highest (>43 MET-h/week) & 102 & $9.0(2.0$ to 16.0$)$ \\
\hline $\mathrm{p}$ Value & & 0.02 \\
\hline \multicolumn{3}{|l|}{ Smoking status } \\
\hline Never smoked & 216 & Ref \\
\hline Ex-smoker & 147 & $-1.9(-7.0$ to 3.2$)$ \\
\hline Current smoker & 31 & $-4.5(-14.1$ to 5.0$)$ \\
\hline $\mathrm{p}$ Value & & 0.56 \\
\hline \multicolumn{3}{|l|}{ BMl category } \\
\hline Normal weight $\left(<25 \mathrm{~kg} / \mathrm{m}^{2}\right)$ & 230 & Ref \\
\hline Overweight $\left(25\right.$ to $<30 \mathrm{~kg} / \mathrm{m}^{2}$ ) & 144 & $-9.1(-14.2$ to -4.1$)$ \\
\hline Obese $\left(\geq 30 \mathrm{~kg} / \mathrm{m}^{2}\right)$ & 20 & $-10.3(-21.4$ to 0.8$)$ \\
\hline $\mathrm{p}$ Value & & 0.001 \\
\hline \multicolumn{3}{|l|}{ Work grade } \\
\hline Lowest & 81 & Ref \\
\hline Intermediate & 155 & $-0.3(-6.0$ to 5.4$)$ \\
\hline Highest & 158 & $-2.8(-10.4$ to 4.8$)$ \\
\hline $\mathrm{p}$ Value & & 0.75 \\
\hline \multicolumn{3}{|l|}{ Highest educational attainment } \\
\hline None & 31 & Ref \\
\hline 0-level/A-level & 219 & $5.1(-5.0$ to 15.3$)$ \\
\hline Degree or higher & 144 & $11.7(0.3$ to 23.0$)$ \\
\hline $\mathrm{p}$ Value & & 0.04 \\
\hline \multicolumn{3}{|l|}{ SF-36 General health perception } \\
\hline Lowest $(<67)$ & 113 & Ref \\
\hline Low-moderate (67-77) & 115 & $-2.2(-8.6$ to 4.1$)$ \\
\hline Moderate (77-87) & 86 & $1.9(-5.0$ to 8.7$)$ \\
\hline High $(>87)$ & 80 & $6.3(-0.9$ to 13.6$)$ \\
\hline $\mathrm{p}$ Value & & 0.13 \\
\hline
\end{tabular}

Model adjusted for age and mutually for all presented variables.

BMI, body mass index; MET, metabolic equivalent of task; MVPA, moderate-to-vigorous physical activity; SF-36, Short-Form 36 Health Survey.

(8.6-50.3) $\mathrm{min} /$ day less accelerometer-assessed sedentary time at follow-up, after adjusting for other covariates and total wear time.

Older age, obesity, lower education and poor general health perception were also associated with lower physical activity levels at follow-up. The difference in accelerometer-assessed activity between participants younger than 50 years and those older than 55 years was 82.1 (115.3-48.8) cpm; between lower and higher education, $73.9(12.7-135.0) \mathrm{cpm}$; obese and normal weight persons, $62.7(102.8-2.6) \mathrm{cpm}$; those perceiving their level of health as low versus high, 41.9 (2.7-81.1) cpm. Older age and lower education were associated with objectively assessed sedentary time at follow-up. Participants younger than 50 years at baseline recorded on average 20.5 (2.2-38.7) $\mathrm{min} /$ day less accelerometer-assessed sedentary time compared with those older than 55 years. Participants with higher compared with the lowest education recorded $42.0(8.3-75.7) \mathrm{min} /$ day less sedentary time. 


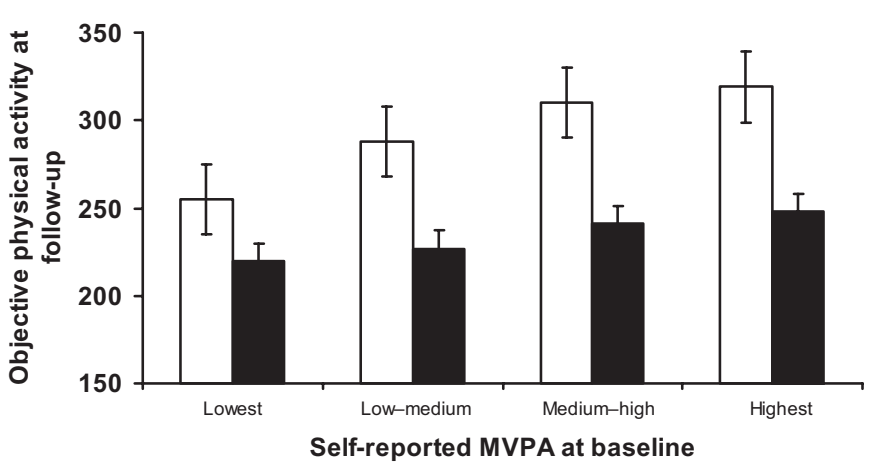

Figure 1 Levels of objectively assessed physical activity at follow-up in relation to quartile of self-reported moderate-to-vigorous physical activity (MVPA) at baseline. Values are means \pm SEM, adjusted for age, sex, body mass index category, smoking, education, employment grade, Short-Form 36 Health Survey quartile. Open bars are counts per minute, and filled bars are total activity (min/day).

\section{DISCUSSION}

The main results of the present study show that physical activity behaviour in middle age is associated with physical activity in later life after 13 years of follow-up, suggesting that the habits in adulthood are partly tracked into older age. We also found factors that are related to physical activity, such as education, BMI and self-rated health in middle age to predict physical activity in older age. In contrast, only age, physical activity and education predicted sedentary behaviour at follow-up.

\section{Comparison with other studies}

The present sample demonstrated higher activity levels (323.7 cpm) compared with other community-based samples of older adults, such as English adults aged 70-75years $(237.8 \mathrm{cpm})^{19}$ and US participants aged $\geq 70$ years in the NHANES study $(188.9 \mathrm{cpm}){ }^{20}$ However, the present study consisted of a healthy subsample of the Whitehall II occupational cohort representing a more privileged population than the general community. In addition, Davis et a ${ }^{19}$ demonstrated that physical activity declined steeply with age, and our sample was slightly younger (average age 66 years at the time of Actigraph data collection) than in the aforementioned studies. Most of the existing research on physical activity patterns in older adults has been cross-sectional. Our findings are consistent with the results from a community-dwelling sample of older British adults aged 65 years or older, which showed that objectively measured activity was associated with age, general health, disability, diabetes and BMI. ${ }^{17}$ Similar findings have been observed in several other studies of older adults that have employed objective physical activity assessment. ${ }^{19-21}$ There are few previous longitudinal data on physical activity patterns across the life course in the same cohort of individuals. In a sample of 881 Canadian adults, the 22-year trajectory in self-reported leisure-time physical activity was modified by baseline age. ${ }^{22}$ In the Aerobics Center Longitudinal Study, lifestyle factors, including physical activity, $\mathrm{BMI}$ and smoking, were related to trajectories in cardiorespiratory fitness independent of age. ${ }^{23}$ This finding is in agreement with our findings on self-rated health and is particularly relevant to the older people given that cardiorespiratory fitness has been shown to decline at an accelerated rate after 45 years of age. ${ }^{23}$

\section{Education and physical activity}

Leisure-time physical activity and sedentary behaviour has been consistently associated with education in a number of studies across a range of different countries, including the USA, ${ }^{24}$
Canada $^{22}$ and in several European countries. ${ }^{25-28}$ Adverse socioeconomic position across the life course has also been associated with an increased cumulative risk of physical inactivity in older age, as demonstrated in the British Women's Heart and Health Study. ${ }^{9}$ However, a limitation of this body of work is the reliance on self-reported physical activity levels, which might introduce biases. In the recent Health Survey for England study, there were no differences in 7-day accelerometrybased measures of moderate-to-vigorous physical activity across household income groups. ${ }^{29}$ The present data suggest that education, but not social position (as indexed by the British civil service employment grade), was associated with objective measures of physical activity and sedentary time. Our findings are therefore consistent with the notion that the social gradient in leisure-time physical activity can be primarily explained through better health knowledge gained during longer educational careers. ${ }^{30}$

\section{Obesity and sedentary time}

We found that obesity at baseline was associated with lower physical activity at follow-up, after controlling for baseline levels of physical activity. The nature of the association between obesity and physical activity is most likely bidirectional in that habitual physical activity across the life course is associated with lower weight gain, ${ }^{31} 32$ but obesity is also a barrier towards physical activity. For example, in a sample of healthy adults, BMI and fat mass at baseline predicted sedentary behaviour at 5.6 years of follow-up, although the reverse association was not evident. ${ }^{33}$ In the present study, moderate-to-vigorous physical activity at baseline was not associated with BMI at follow-up (B coefficient $=0.004,95 \% \mathrm{CI}-0.005$ to 0.014 ), after accounting for baseline levels of adiposity, which further suggests that the direction of the association is more predominantly from obesity to physical inactivity. In agreement with our findings, obesity was associated with a greater rate of decline in cardiorespiratory fitness over 20 years of follow-up in the Aerobics Center Longitudinal Study. ${ }^{23}$

Interestingly, there were no correlations between self-reported and objective sedentary time. This finding might indicate that sedentary behaviour is not stable across time, in particular moving from mid-life into older age. However, this might also reflect a measurement issue as accurate assessment of sedentary behaviour continues to be a controversial area in epidemiology. ${ }^{34}$ A recent study using data from NHANES indicated weak but significant associations between self-reported TV viewing time with accelerometer-derived total sedentary time, although the associations were not significant in the working population. ${ }^{35}$ Thus, given that the majority of the present sample was in employment at the time of the baseline assessment, our findings are consistent with the existing data. However, it is possible that self-reported TV time or sitting is able to better capture prolonged periods of sedentary activity than the present methods of objective assessment. Indeed, the accelerometry device used in the present study could not distinguish between sitting and standing, although results were not different when more conservative cut points $(0 \mathrm{cpm})$ were used to distinguish sedentary activity.

\section{Strengths and limitations}

Most of the existing research on physical activity patterns in older adults has been cross-sectional, and few studies have tracked individuals longitudinally from mid-life into older age. The major strength of this study was the longitudinal design and use of accelerometry-based measures of physical activity. 


\section{What is already known on this subject}

- Physical activity is important for maintaining health in older age.

- Numerous factors might be important in determining physical activity behaviour across the life course, although few studies have tracked individuals longitudinally from mid-life into older age.

\section{What this study adds}

- Adiposity, education, functional health and physical activity behaviour measured in middle age were all predictive of physical activity after 13 years of follow-up when participants were entering early old age.

- Successful intervention might entail targeting behaviour at life stages before older age.

Although the strengths of the associations between self-reported and objectively assessed physical activity were modest, this is consistent with previous validation studies because it is well accepted that self-reported measures can introduce bias. ${ }^{36}$ The participants from the Whitehall II study are well characterised, although the present study consisted of a healthy subsample of the cohort and therefore might not be representative of the general community. Since accelerometry measures were only collected over 1 week, this may not truly reflect habitual physical activity levels. Nevertheless, other data in British adults have demonstrated strong test-retest reliability for moderate-tovigorous physical activity ( $r=0.89$ for men, $r=0.76$ in women), measured using accelerometers for two non-consecutive weeks over a month period. ${ }^{37}$ In addition, swimming is not recorded by the Actigraph device, which could lead to an underestimation of physical activity levels, although the self-reported diaries suggested that this occurred infrequently with $<11 \%$ of the sample reporting such activity at any point of the observation period.

In summary, physical activity behaviour in mid-life was associated with objectively assessed activity in older age after 13 years of follow-up. This suggests that the physical activity habits in adulthood are partly tracked into older age. Successful intervention might therefore entail targeting behaviour at life stages before older age.

Acknowledgements We acknowledge the contributions of Sir Professor Michael Marmot to the study design, and Bev Murray, Livia Urbanova, Amanda Rossi and the Whitehall II study team to data collection.

Contributors $\mathrm{MH}$ had full access to the data and takes responsibility for the integrity of the data and accuracy of the data analyses. All authors contributed to the concept and design of study, drafting and critical revision of the manuscript.

Funding This research was supported by the British Heart Foundation, the Medical Research Council and the BUPA Foundation, UK. The Whitehall II study is additionally supported by the National Institutes of Health (R01HL36310; R01AG013196;

R01AG034454), USA.

Competing interests None.

Patient consent Obtained.

Ethics approval Ethics approval was provided by University College London Hospital (UCLH) committee on the Ethics of Human Research.
Provenance and peer review Not commissioned; externally peer reviewed.

\section{REFERENCES}

1. Stessman J, Hammerman-Rozenberg R, Cohen A, et al. Physical activity, function, and longevity among the very old. Arch Intern Med 2009;169:1476-83.

2. Paterson DH, Warburton DE. Physical activity and functional limitations in older adults: a systematic review related to Canada's Physical Activity Guidelines. Int J Behav Nutr Phys Act 2010; 7:38.

3. Hamer M, Chida Y. Physical activity and risk of neurodegenerative disease: a systematic review of prospective evidence. Psychol Med 2009;39:3-11.

4. Garcia AW, Pender NJ, Antonakos CL. Changes in physical activity beliefs and behaviors of boys and girls across the transition to junior high school. J Adolesc Health 1998;22:394-402.

5. Burke V, Beilin LJ, Dunbar D. Changes in health-related behaviours and cardiovascular risk factors in young adults: associations with living with a partner. Prev Med 2004;39:722-30.

6. Raymore L, Barber B, Eccles J. Leaving home, attending college, partnership and parenthood: the role of life transition events in leisure pattern stability from adolescence to young adulthood. J Youth Adolesc 2001;30:197-223.

7. McIntyre CA, Rhodes RE. Correlates of leisure-time physical activity during transitions to motherhood. Women Health 2009;49:66-83.

8. Allender S, Foster C, Boxer A. Occupational and nonoccupational physical activity and the social determinants of physical activity: results from the Health Survey for England. J Phys Act Health 2008;5:104-16.

9. Hillsdon M, Lawlor DA, Ebrahim S, et al. Physical activity in older women: associations with area deprivation and with socioeconomic position over the life course: observations in the British Women's Heart and Health Study. J Epidemiol Community Health 2008;62:344-50.

10. Cleland VJ, Ball K, Magnussen C, et al. Socioeconomic position and the tracking of physical activity and cardiorespiratory fitness from childhood to adulthood. Am J Epidemiol 2009;170:1069-77.

11. Warren JM, Ekelund U, Besson $\mathrm{H}$, et al; Experts Panel. Assessment of physical activity - a review of methodologies with reference to epidemiological research: a report of the exercise physiology section of the European Association of Cardiovascular Prevention and Rehabilitation. Eur J Cardiovasc Prev Rehabil 2010;17:127-39.

12. Marmot M, Brunner E. Cohort profile: the Whitehall II study. Int J Epidemiol 2005; 34:251-6.

13. Singh-Manoux A, Hillsdon M, Brunner E, et al. Effects of physical activity on cognitive functioning in middle age: evidence from the Whitehall $\|$ prospective cohort study. Am J Public Health 2005;95:2252-8.

14. Taylor HL, Jacobs DR Jr, Schucker B, et al. questionnaire for the assessment of leisure time physical activities. J Chronic Dis 1978;31:741-55

15. Sabia S, Dugravot A, Kivimaki M, et al. Effect of intensity and Type of physical activity on mortality: results from the Whitehall II cohort study. Am J Public Health 2012 102:698-704.

16. Ware JE. Measuring patient's views: the optimum outcome measure. SF36: a valid reliable assessment of health from the patient's point of view. BMJ 1993:306:1429-40.

17. Harris TJ, Owen CG, Victor CR, et al. What factors are associated with physical activity in older people, assessed objectively by accelerometry? Br J Sports Med 2009;43:442-50.

18. Choi L, Liu Z, Matthews CE, et al. Validation of accelerometer wear and nonwear time classification algorithm. Med Sci Sports Exerc 2011;43:357-64

19. Davis MG, Fox KR, Hillsdon M, et al. Objectively measured physical activity in a diverse sample of older urban UK adults. Med Sci Sports Exerc 2011; 43:647-54.

20. Troiano RP, Berrigan D, Dodd KW, et al. Physical activity in the United States measured by accelerometer. Med Sci Sports Exerc 2008;40:181-8.

21. Yoshiuchi K, Nakahara R, Kumano $\mathrm{H}$, et al. Yearlong physical activity and depressive symptoms in older Japanese adults: cross-sectional data from the Nakanojo study. Am J Geriatr Psychiatry 2006;14:621-4.

22. Barnett TA, Gauvin L, Craig CL, et al. Modifying effects of sex, age, and education on 22-year trajectory of leisure-time physical activity in a Canadian cohort. $J$ Phys Activ Health 2007:4:153-66.

23. Jackson AS, Sui X, Hébert JR, et al. Role of lifestyle and aging on the longitudinal change in cardiorespiratory fitness. Arch Intern Med. 2009;169:1781-7.

24. Simpson ME, Serdula M, Galuska DA, et al. Walking trends among U.S. adults: the Behaviorar Risf Factor Surveillance System, 1987-2000. Am J Prev Med 2003;25:95-100.

25. Borodulin K, Laatikainen T, Lahti-Koski M, et al. Association of age and education with different types of leisure time physical activity among 4437 Finnish adults. J Phys Activ Health 2008:5:242-51.

26. Lynch JW, Kaplan GA, Salonen JT. Why do poor people behave poorly ? Variation in adult health behaviours and psychosocial characteristics by stages of the socioeconomic lifecourse. Soc Sci Med 1997:44:809-19.

27. Vaz de Almeida MD, Graca P, Afonso C, et al. Physical activity levels and body weight in a nationally representative sample in the European Union. Public Health Nutr 1999;2:105-13.

28. Stamatakis E, Hillsdon M, Mishra G, et al. Television viewing and other screenbased entertainment in relation to multiple socioeconomic status indicators and area 
deprivation: the Scottish Health Survey 2003. J Epidemiol Comm Health 2009;63:734-40.

29. Craig R, Mindell J, Hirani V; On behalf of the Joint health surveys Unit. The Health Survey for England 2008. Volume 1: Physical Activity and Fitness/ Chapter 3: Accelerometry in Adults. Leeds: The Information Centre for Health and Social Care. http://www.ic.nhs.uk/pubs/hse08physicalactivity (accessed 1 Apr 2010).

30. Wardle J, Steptoe A. Socioeconomic differences in attitudes and beliefs about healthy lifestyles. J Epidemiol Community Health 2003;57:440-3.

31. Hankinson AL, Daviglus ML, Bouchard C, et al. Maintaining a high physical activity level over 20 years and weight gain. JAMA 2010;304:2603-10.

32. Sternfeld B, Wang H, Quesenberry CP Jr, et al. Physical activity and changes in weight and waist circumference in midlife women: findings from the Study of Women's Health Across the Nation. Am J Epidemiol 2004;160:912-22.
33. Ekelund U, Brage $\mathrm{S}$, Besson $\mathrm{H}$, et al. Time spent being sedentary and weight gain in healthy adults: reverse or bidirectional causality? Am J Clin Nutr 2008;88:612-17.

34. Clark BK, Sugiyama T, Healy GN, et al. Validity and reliability of measures of television viewing time and other non-occupational sedentary behaviour of adults: a review. Obes Rev 2009;10:7-16.

35. Clark BK, Healy GN, Winkler EA, et al. Relationship of television time with accelerometer-derived sedentary time: NHANES. Med Sci Sports Exerc 2011:43:822-8.

36. Harris TJ, Owen CG, Victor CR, et al. A comparison of questionnaire, accelerometer and pedometer: measures in older people. Med Sci Sports Exerc 2009; 41:1392-402.

37. Joint Health Surveys Unit. Health Survey for England Physical Activity Validation Study: Substantive Report. Leeds: Health and Social Care Information Centre, 2007. 